\title{
Hiperglucemia refractaria al tratamiento por causa de resistencia a la insulina tipo $\mathrm{B}$ : reto diagnóstico
}

\author{
Refractory hyperglycemia due to insulin type B resistance: diagnostic \\ challenge
}

Gómez $A M^{1}$, Gómez $C^{2}$, Leguizamón $G^{3}$, Imitola $A^{3}$

\author{
${ }^{1}$ Médica internista endocrinóloga, jefe de la Unidad de \\ Endocrinología Hospital Universitario San Ignacio, Pontificia \\ Universidad Javeriana. Bogotá, Colombia. \\ ${ }^{2}$ Médica internista endocrinóloga. Hospital Universitario San \\ Ignacio, Pontificia Universidad Javeriana. Bogotá, Colombia. \\ ${ }^{3}$ Médico internista, residente de endocrinología. Hospital \\ Universitario San Ignacio, Pontificia Universidad Javeriana. \\ Bogotá, Colombia. \\ Dirección correspondencia: Ana María Gómez \\ E mail: amgomezm5@gmail.com \\ Posibles conflictos de interés: Ninguno. \\ Fecha de recepción: 19/09/2018 \\ Fecha de aceptación: 12/10/2018
}

\section{Resumen}

$\mathrm{L}$ a resistencia a la insulina tipo $B$ es una entidad que se caracteriza por hiperglucemia refractaria al tratamiento con insulina asociada a enfermedades autoinmunes. La prevalencia es baja, no obstante, el diagnóstico oportuno es fundamental por el impacto favorable del tratamiento en los desenlaces clínicos. Se han descrito en la literatura 116 casos. Presentamos el caso de una paciente con resistencia a la insulina tipo B, quien obtuvo mejoría de control glucémico registrado por monitoreo continuo de glucosa (MCG) al iniciar tratamiento inmunomodulador.

Palabras clave: hiperglucemia, resistencia a la insulina, enfermedad autoinmune.

\section{Abstract}

Insulin resistance type $B$ is an entity characterized by hyperglycemia refractary to insulin associated to autoinmune disease. The prevalence is low, however, well-timed diagnose is fundamental because of the favorable impact of treatment in clinical outcomes. 116 case reports of insulin resistance type $B$ have been described in worlwide literature. We describe the case of a patient with insulin resistance type $B$, who achieved improve- ment of glucose control registered by continuos glucose monitoring after initiation of inmunomodulator treatment.

Key words: hyperglycemia, insulin resistance, autoinmune disorder.

\section{Introducción}

El síndrome de resistencia a la insulina tipo B es una entidad que genera alteración de los niveles de hiperglucemia refractaria al tratamiento o, de manera menos frecuente, hipoglucemia, según la estimulación que genere el anticuerpo en el receptor de la insulina. El tratamiento principal son los inmunomoduladores, ya que en estos pacientes, a pesar de altas dosis de insulina, no se logra un control metabólico adecuado $^{(1,2)}$.

Describimos el caso de una paciente con resistencia a la insulina tipo B asociada a lupus eritematoso sistémico (LES), quien presentó mejoría de los niveles de glucemia después del inicio del tratamiento inmunomodulador con metilprednisolona, azatioprina, ciclofosfamida e inmunoglobulina. De resaltar, en este caso pudimos evaluar la mejoría de los niveles de glucemia a través del uso de MCG durante seis días.

\section{Caso clínico}

Paciente de género femenino de 35 años de edad, quien consulta por cuadro clínico de cuatro días de evolución de astenia, adinamia, náuseas, poliuria, polidipsia y debilidad muscular en extremidades. Como antecedentes, tenía diagnóstico de diabetes mellitus (DM) tipo 1 con HbA1c 21,8\% y LES con síndrome nefrótico, los cuales fueron diagnosticados tres meses antes de la presentación del cuadro clínico. Había presentado tres hospitalizaciones por cetoacidosis diabética (CAD) y actividad de LES desde el diagnóstico. Se encontraba en tratamiento con insulina en esquema basal-bolo DDTI: 4.4 UI/kg/día sin adecuado control glucémico y con inmunomoduladores (esteroide, azatioprina y cloroquina). Al ingreso, la paciente presentó glucometría de $437 \mathrm{mg} / \mathrm{dl}$, IMC de 17,8 Kg/ 
Figura 1. Acantosis en localización atípica, dorso de pies.

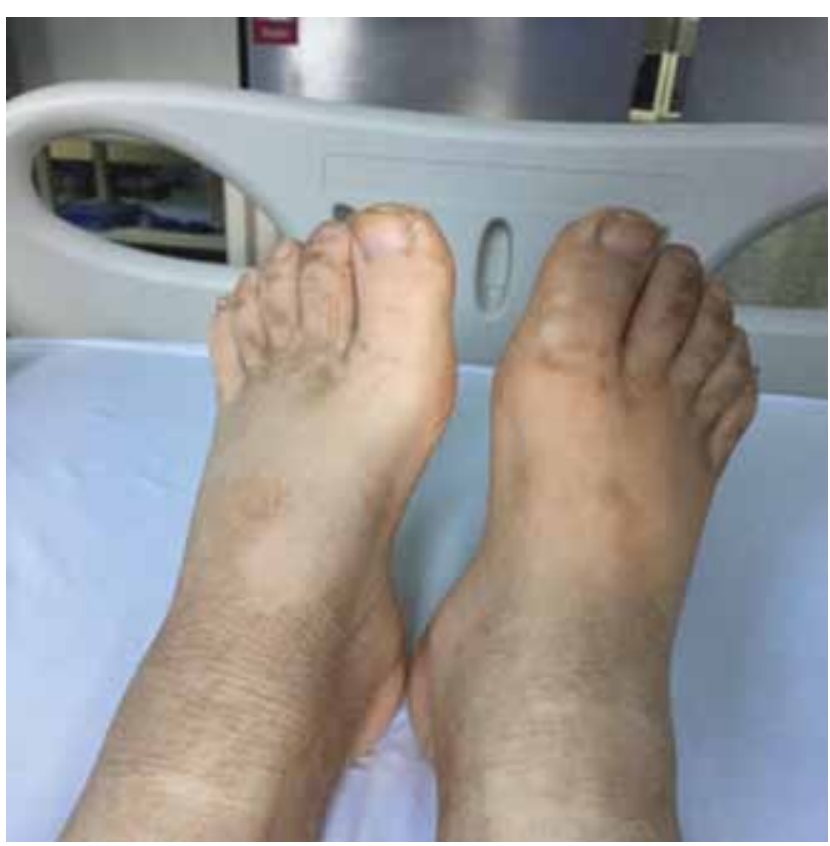

$\mathrm{m}^{2}$ y se identificó acantosis nigricans en pliegue anterior de pies (figura 1) además de paresia, disestesias e hiporreflexia de miembros inferiores. Se realizaron paraclínicos con evidencia de glucosa sérica de $571 \mathrm{mg} / \mathrm{dl}$, anemia, proteinuria, hipoalbuminemia y complemento consumido. Se descartó CAD y con base en el examen físico y punción lumbar, se diagnosticó síndrome de Guillain Barré, recibiendo tratamiento con inmunoglobulina. Dado que no se lograba adecuado control glucométrico, se inició infusión intravenosa (IV) de insulina, alcanzando una dosis de hasta $61.5 \mathrm{UI} / \mathrm{Kg} /$ día, con persistencia de glucometrías elevadas entre 250 y $300 \mathrm{mg} / \mathrm{dl}$. Se llevó a junta médica de endocrinología y reumatología, considerándose diagnóstico de resistencia a la insulina tipo B y con base en la literatura disponible, se decidió dar tratamiento con ciclofosfamida $1 \mathrm{~g}$ IV en dosis única más metilprednisolona $1 \mathrm{~g}$ IV cada día durante tres días. Antes, durante y después del tratamiento inmunomodulador, se realizó MCG durante seis días, en el cual se registró mejoría de control glucémico a partir de las 48 horas del inicio del tratamiento (figura 2), con un descenso concomitante y progresivo de las dosis de insulina. A los 25 días de administración de los inmunomoduladores, se logró la suspensión de insulina exógena. Como estudios adicionales, se realizaron DHEA-S: $32,09 \mathrm{mcg} / \mathrm{dl}(60,9-337)$, testosterona total: $0,048 \mathrm{ng} / \mathrm{ml}(0,06-0,82)$, perfil lipídico cuyo resultado fue normal, anticuerpos AntiGAD: 1,30 U/ml (positivo mayor 1,05), anticuerpos antiinsulina: 0,10 (negativo menor de 0,95), anticuerpos contra los islotes pancreáticos (ICA): 0,1 (negativo menor a 0,95 ) y adiponectina $10,3 \mathrm{mcg} / \mathrm{ml}$ (rango mujeres de 30-39 años: 1,9-20,6). No se pudieron procesar los anticuerpos antirreceptor de insulina por dificultades admi-
Figura 2. Monitoreo continuo de glucosa iPro2 realizado durante seis días, se inició el primer día de la administración del tratamiento inmunomodulador. Se observa a partir de las $\mathbf{4 8}$ horas mejor control glucométrico, logrando reducción de dosis de insulina.

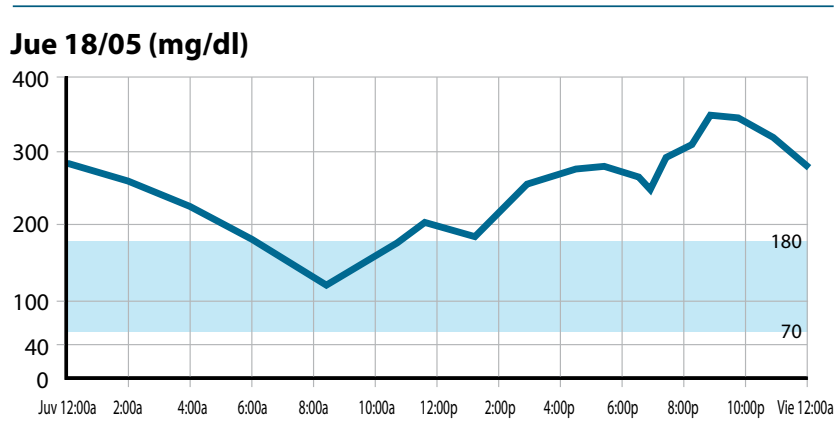

Vie 19/05 (mg/dl)

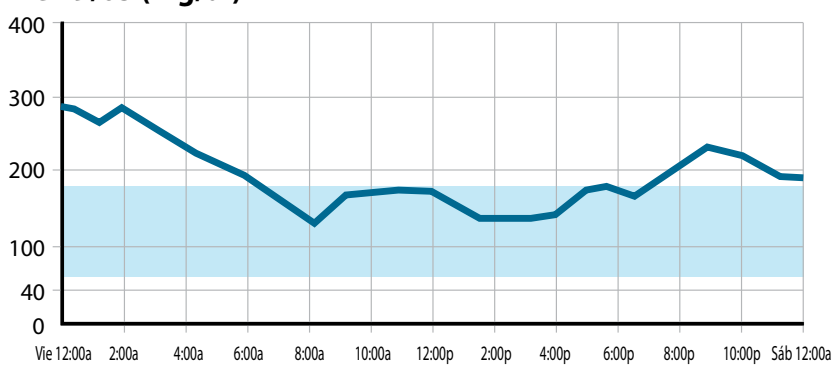

Sáb 20/05 (mg/dl)

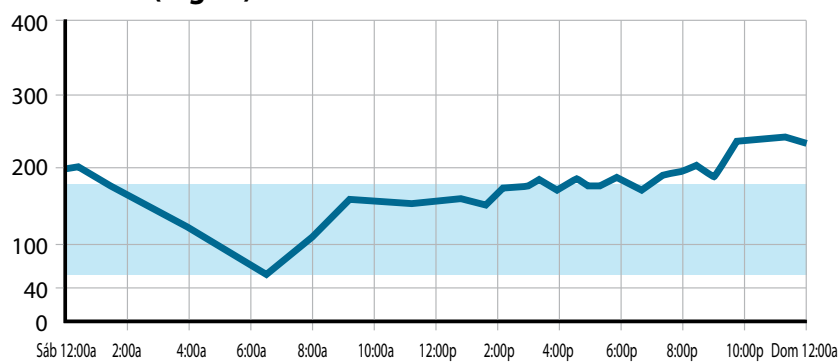

Dom 21/05 (mg/dl)

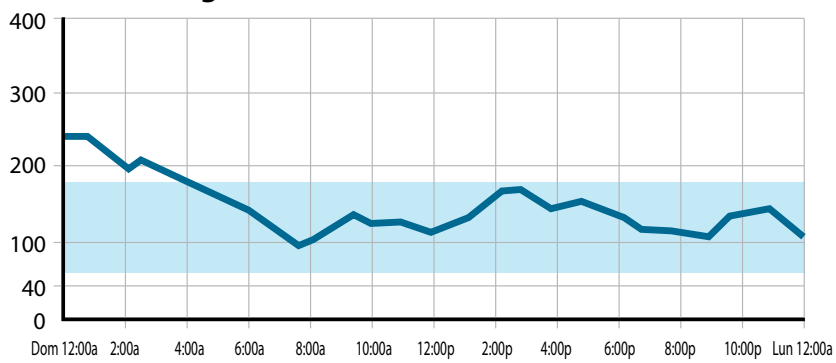

Lun 22/05 (mg/dl)

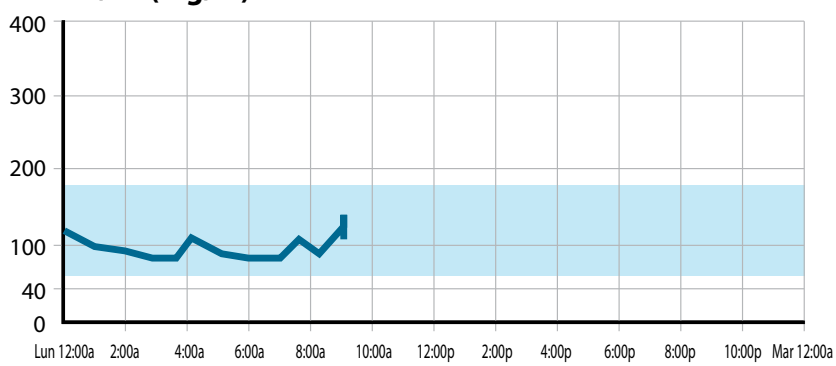


nistrativas y no procesamiento en Colombia. Tras evolución clínica favorable, se dio alta médica con azatioprina $50 \mathrm{mg} /$ día y prednisolona $5 \mathrm{mg} /$ día. Se realizó seguimiento con control glucométrico completando un año sin requerimiento de insulina y adecuada recuperación de peso.

\section{Discusión}

Ante un paciente con hiperglucemia persistente y refractaria a las dosis altas de insulina, se debe sospechar la presencia de insulinorresistencia asociada a una alteración autoinmune o del receptor de insulina, específicamente cuando las dosis de insulina superan las $3 \mathrm{UI} / \mathrm{kg} /$ día y aun así no se logra un control glucémico adecuado ${ }^{(1)}$.

En el caso de esta paciente de edad adulta y cuyo cuadro clínico incluía la presencia de enfermedad autoinmune (LES), la primera posibilidad diagnóstica fue la insulinorresistencia tipo B, siendo menos probables otras causas de resistencia a la insulina.

Dentro de los diagnósticos diferenciales está la insulinorresistencia tipo A, la cual no se asocia a enfermedades autoinmunes y se presenta a edades más tempranas; también se encuentran los síndromes de Donohue (Leprechaunismo), de Rabson-Mendenhall y HAIR-AN (hiperandrogenismo, resistencia a la insulina y acantosis nigricans), cuyas manifestaciones clínicas son congénitas y donde el último de los descritos se asocia a obesidad, la cual no estaba presente en esta paciente ${ }^{(1)}$.

La resistencia a la insulina tipo B es una patología que se presenta más frecuentemente entre los 30 y 50 años de edad y es causada por la aparición de autoanticuerpos contra el receptor de insulina, adquiriendo así el rótulo de enfermedad autoinmune. Se asocia a otras alteraciones autoinmunes, como LES, enfermedad mixta del tejido conectivo y a enfermedades autoinmunes tiroideas, dermatológicas, hematológicas y hepáticas. También se puede asociar a neoplasias hematológicas como linfoma Hodgkin y mieloma múltiple (tabla 1$)^{(1,2,3)}$.

Se manifiesta por hiperglucemia marcada refractaria a dosis convencionales de insulina exógena, con altos requerimientos de insulina, aunque en un pequeño porcentaje de los pacientes se puede asociar a hipoglucemia en ciertos periodos de la enfermedad; también se observa acantosis nigricans típica y atípica (área perioral, periorbitaria o en pliegues poco usuales) y bajo peso esperado para el grado de hiperinsulinismo (usualmente con IMC $<30 \mathrm{~kg} / \mathrm{m}^{2}$ ). Adicionalmente, se puede encontrar hiperandrogenismo (amenorrea, acné e hirsutismo) con ovario poliquístico y anemia 4. En la paciente del caso, hubo hiperglucemia con bajo peso, sin periodos de hipoglucemia, con acantosis nigricans únicamente en pliegue anterior de ambos pies, pero sin evidencia de hiperandrogenismo.

En cuanto a hallazgos de laboratorio, en esta enfermedad se observa una marcada elevación de los niveles de glucosa e insulina endógena y presencia de autoanticuerpos contra el
Tabla 1. Enfermedades asociadas a insulinorresistencia tipo B.

\begin{tabular}{l|c}
\multicolumn{1}{c|}{ Enfermedad } & Frecuencia \\
\hline Lupus eritematoso sistémico & $46 \%-62 \%$ \\
\hline $\begin{array}{l}\text { Esclerodermia, dermatomiositis, síndrome de } \\
\text { sobreposición, cirrosis biliar primaria }\end{array}$ & $5,9 \%-15 \%$ \\
\hline $\begin{array}{l}\text { Enfermedad de Graves, Hipotiroidismo } \\
\text { primario, tiroiditis autoinmune. }\end{array}$ & $5,9 \%$ \\
\hline Mieloma múltiple, linfoma Hodgkin & $4,4 \%-10 \%$ \\
\hline
\end{tabular}

Adaptado de 3 y 4.

receptor de insulina, puede haber aumento de la adiponectina y de los andrógenos, anemia y leucopenia con neutropenia. Los triglicéridos pueden estar normales o bajos. Los anticuerpos antiinsulina son usualmente negativos ${ }^{(1)}$. En esta paciente, los niveles de adiponectina fueron normales y los anticuerpos antiinsulina fueron negativos.

Los pilares del tratamiento son dos, control de la hiperglucemia e hipoglucemia y modulación del proceso autoinmune. Con respecto al control de la hiperglucemia, se indica titular las dosis de insulina exógena a la cantidad necesaria para lograr niveles de glucosa normales o cercanos a los normales, incluso si son muy altas, se recomienda administrarla IV; se han reportado casos en los que los requerimientos han llegado a ser de $30.000 \mathrm{UI} /$ día. El uso de antidiabéticos orales no ha sido exitoso. En los casos de hipoglucemia, se ha encontrado respuesta con el uso de esteroides, con dosis equivalentes de prednisolona entre 20-150 mg al día, con lo cual usualmente se revierte la hipoglucemia a las 24 horas de su administración $^{(1,3)}$.

En cuanto a la terapia inmunomoduladora, se han intentado llevar a cabo varios esquemas terapéuticos con glucocorticoides a dosis altas, ciclofosfamida, inmunoglobulina, azatioprina, micofenolato, rituximab e incluso plasmaféresis en casos severos y refractarios ${ }^{(1,2)}$.

El esquema que ha demostrado mayor eficacia es el implementado por los Institutos Nacionales de Salud de los Estados Unidos (NIH), con una aparente reducción de mortalidad, información basada en el reporte de una cohorte de pacientes seguida durante 28 años, la cual se comparó con los casos reportados previamente en la literatura. Este esquema incluye pulsos de glucocorticoides a dosis altas, junto con ciclofosfamida y rituximab (tabla 2$)^{(1)}$. En el caso de esta paciente, se dio manejo con ciclofosfamida y metilprednisolona IV con una muy buena respuesta; sin embargo, no se utilizó rituximab, dado que en Colombia y para el momento del tratamiento de la paciente, este medicamento no tenía registro sanitario para este uso, y el proceso de formulación y dispensación de medicamentos sin indicación INVIMA para patologías poco comunes, se encontraba en transición, lo cual limitó su formulación. 
Tabla 2. Esquema de tratamiento NIH.

\section{Para insulinorresistencia tipo B}

\section{Rituximab}

\section{Dosis:}

$750 \mathrm{mg} / \mathrm{m}^{2}$ de superficie corporal, endovenoso

\section{Administración:}

Dosis inicial y a las dos semanas (1 ciclo)

Luego cada 3-4 meses si persiste la enfermedad.

Pulsos de glucocorticoides a altas dosis

\section{Metilprednisolona}

1 IV por 2-3 días al inicio y con cada dosis de rituximab.

Cada 4-6 semanas si la enfermedad permanece activa

o

\section{Dexametasona}

$40 \mathrm{mg}$ VO c/día durante cuatro días.

\section{Ciclofosfamida}

Se inicia con el rituximab

$500 \mathrm{mg}$ IV en 2 ciclos

o

100 mg VO c/día hasta que la remisión se alcance.

Adaptado de 2

El pronóstico de estos pacientes es variable. De acuerdo con lo reportado por la cohorte de pacientes de los NIH, el 33\% presenta remisión espontánea, otro 33\% remite luego de la terapia inmunomoduladora y el otro tercio no logra remisión a pesar de la terapia. El rango de tiempo en el cual se logra una respuesta va desde los 2,5 hasta los 27 meses posterapia. En esta paciente, la respuesta fue mucho más temprana, logrando el retiro de la insulina y remisión a los 25 días del manejo con ciclofosfamida y metilprednisolona; sin embargo, no es posible determinar si parte de la remisión se haya debido también al efecto de la inmunoglobulina requerida para el control del síndrome de Guillen Barré al inicio de su hospitalización ${ }^{(2,4)}$.

La mortalidad de estos pacientes es de $54 \%$ a los 10 años de diagnóstico, casi la mitad explicadas por las patologías autoinmunes concomitantes, principalmente el LES. Nuestra paciente persiste con remisión de la insulinorresistencia tipo B y control del LES tras un año de seguimiento ${ }^{(4)}$.

El diagnóstico de esta paciente se apoyó en la presentación del cuadro clínico, los hallazgos de laboratorio, la respuesta a la terapia inmunomoduladora y descarte de otras entidades, a pesar de no contar con la prueba de laboratorio para evaluar la presencia autoanticuerpos contra el receptor de insulina.

Tanto la imposibilidad de realizar la prueba de autoanticuerpos contra el receptor de insulina como las dificultades para el uso de terapias biológicas, como lo fue el rituximab en este caso, son limitaciones para las cuales deben buscarse soluciones en nuestro sistema de salud, en pro de brindar un manejo adecuado de esta patología.

\section{Conclusión}

La resistencia a la insulina tipo B es una patología poco frecuente que debe sospecharse ante hiperglucemia refractaria a altas dosis de insulina y la presencia de enfermedades autoinmunes concomitantes. Su tratamiento se centra en terapia inmunomoduladora y su pronóstico vital depende del control de las patologías autoinmunes o neoplásicas asociadas.

\section{Referencias}

1. Willard D, Stevenson M, and Steenkamp D. Type B insulin resistance síndrome. Curr Opin Endocrinol Diabetes Obes. 2016, 23:318-323.

2. Malek R, Chong A, Lupsa B, Lungu A, Cochran A, Soos M, et al. Treatment of Type B Insulin Resistance: A Novel Approach to Reduce Insulin Receptor Autoantibodies. J Clin Endocrinol Metab. 2010, 95: 3641-3647.

3. Zhang $\mathrm{S}$, Wang $\mathrm{G}$ and Wang J. Type B insulin resistance syndrome induced by systemic lupus erythematosus and successfully treated with intravenous immunoglobulin: case report and systematic review. Clin Rheumatol. 2013, 32:181-188.

4. Arioglu E, Andewelt A, Diabo C, Bell M, Taylor S, And Gorden P. Clinical Course of the Syndrome of Autoantibodies to the Insulin Receptor (Type B Insulin Resistance): A 28-Year Perspective. Medicine. 2002, 81:87-100. 